\title{
Ateş yakınması ile çocuk acile başvuran hastalarda uygunsuz dozda ateş düşürücü kullanma sıklığının ve nedenlerinin belirlenmesi
}

\author{
Determining causes and frequency of misdosing of antipyretics in patients presenting with \\ fever to pediatric emergency
}

\author{
Zeynep Arıkan, Özlem Tekşam, Ateş Kara, Gülsev Kale \\ Hacettepe Üniversitesi Tıp Fakültesi, Çocuk Sağlığı ve Hastalıkları Anabilim Dalı, Ankara, Türkiye
}

\section{Özet}

Amaç: Çocuk Acil'e ateş yakınması ile başvuran hastalara, aileleri tarafından verilen ateş düşürücülerin (parasetamol ve/veya ibuprofen) uygun dozda kullanılıp kullanıımadığını araştırmak ve yanlış dozda ilaç kullanımını etkileyen etmenleri belirlemektir.

Gereç ve Yöntem: Çalışmaya 1 Ocak 2008-31 Mart 2008 tarihleri arasında, 08:00-16:00 saatlerinde ateş yakınması nedeni ile başvuran çocuklar alındı. Hastaların ailelerinin yanıtladığı 30 soruluk bir anket hazırlandı. Çalışma için Hacettepe Üniversitesi Tıp Fakültesinden etik kurul izni (HEK07/138-24) alındı.

Bulgular: Çalışmada 200 hastanın sonuçları değerlendirildi. Hastaların \%54'ünün yanlış dozda ateş düşürücü kullandığı görüldü. Hastaların $\% 58,1$ 'i düşük dozda, \%8,4'ü ise yüksek dozda parasetamol olmak üzere \% 66,5'i yanlış dozda parasetamol almıştı. İbuprofen alan hastaların ise \%27,7'si yetersiz dozda, \%9,6'sı yüksek dozda olmak üzere, \%37,3'üne yanlıș dozda ibuprofen verilmiști. Çocuğun yaș ve kilosu ile anne ve babanın yaşı arttıkça yanlış dozda ateş düşürücü verilme intimalinin arttığı saptandı. Hastaların \%58'inin ateşi kontrol altına alınsa bile acile getirileceği saptandı. Ailelerin \%97'si ateşin zararlı etkileri olduğuna inanıyordu.

Çıkarımlar: Çalışmamızda ateş düşürücü dozunun çoğunlukla doktorlardan öğrenildiği belirtilmesine rağmen; hastaların büyük çoğunluğuna verilen parasetamol ve/veya ibuprofen dozunun yetersiz olduğu görüldü. Yanlış dozda ateş düşürücü verilme nedeninin, uygun ateş düşürücü doz bilgisinin artan yaş veya ağırlık ile güncellenmemesi olduğu düşünüldü. Ayrıca ateş korkusunun çalışma grubumuzda yaygın bir düşünce olduğu saptandı. Yanlış ateş düşürücü kullanma sıklığını ve ateş korkusunu azaltmak için, ailelere ateş ve ateş düşürücü kullanımı hakkında eğitim verilmesi, ailelere eğitim verilirken ağırlığın dikkate alınması gerektiği mutlaka vurgulanmalıdır. (Türk Ped Arş 2012; 47: 114-8)

Anahtar sözcükler: Ateş, ateş düşürücü dozu, asetaminofen, çocuk acil, ibuprofen

\section{Summary}

Aim: The aim of this study was to identify the frequency of misdosing of antipyretics in children presenting with fever to the pediatric emergency department and to identify factors affecting misuse.

Material and Method: This study was conducted between January and March 2008. Children with fever who were admitted between 08:00-16:00 were included in the study. A questionaire including 30 questions was prepared for parents or caregivers. The study approved by the ethics commite of Hacettepe Medical Faculty (HEK07/138-24).

Results: The caregivers of a total of 200 children were included in the study. It was observed that $54 \%$ of the patients received inaccurate doses of antipyretics. $66.5 \%$ of the patients received inaccurate dose of paracetamol including $58.1 \%$ underdose and $8.4 \%$ overdose. $37.3 \%$ of the patients received inaccurate dose of ibuprofen including $27.7 \%$ underdose and $9.6 \%$ overdose. It was found that as the age and weight of the child and the age of the parents increased, the probability of receiving inaccurate dose of antipyretic increased. It was found that $58 \%$ of the patients would have been taken to the emergency department, even if fever subsided. $97 \%$ of the families believed that fever had harmful effects.

Conclusions: Although the dose of antipyretics was reported to be learned from physicians in our study, it was observed that the dose of paracetamol and/or ibuprofen was inadequate in a significant portion of the patients. It was thought that the reason for wrong dosage of antipyretics was lack of updating of appropriate dosage knowledge with increasing age or weight. In addition, fever fobia was found to be a common belief in our study group. To decrease the frequency of inadequate antipyretic use and fever phobia it should be emphasized that families should be educated about fever and use of antipyretics and body weight should be taken into account when educating families. (Turk Arch Ped 2012; 47: 114-8)

Key words: Acetaminophen, fever, dose of antipyretics, ibuprofen, pediatric emergency

Yazışma Adresi/Address for Correspondence: Dr. Özlem Tekşam, Hacettepe Üniversitesi Tıp Fakültesi Çocuk Sağlığı ve Hastalıkları Anabilim Dalı, Ankara, Türkiye Tel: +90 3123051130 E-posta: ozlemt@hacettepe.edu.tr Geliş Tarihi/Received: 12.08.2011 Kabul Tarihi/Accepted: 09.03.2012

Türk Pediatri Arşivi Dergisi, Galenos Yayınevi tarafından basılmıştır. / Turkish Archives of Pediatrics, published by Galenos Publishing 


\section{Giriş}

Ateş, ailelerin en çok endişe duydukları ve nedenini bir an önce bilmek istedikleri bir yakınmadır. Bu nedenle çocuk acile başvuruların önemli bir bölümünü ateși olan çocuklar oluşturmaktadır. Ancak doğal bir savunma mekanizması olduğunun bilinmesi ve doktorlar için etkili bir uyarı olmasına karşın, aileler için ateş önemli bir korku nedeni olma özelliğini korumaktadır. Bu korku nedeniyle çocukta en ufak bir ısı artışı hemen girişim gerektirdiği düşüncesini tetiklemekte, ateş düşürülmez ise beyin hasarı hatta ölüm gibi ciddi sorunlara neden olacağı şeklinde yersiz endişelere neden olmaktadır. Ancak bazı ateşli çocuklarda menenjit, pnömoni, eklem ve kemik enfeksiyonları, idrar yolu enfeksiyonu gibi ciddi bakteriyel enfeksiyon geliştirme riski olabileceği gibi, tam olarak ateş odağı bulunamayan hastalarda da gizli bakteriyemi olma olasııı̆ı bulunmaktadır. Ailelerin yaşadıkları endişeler yanında bu gibi klinik durumların hekimler tarafından iyi ayırd edilmesi gerekmektedir. Tüm bu endişelere rağmen ateşi olan çocuklara yaklaşımın incelendiği çalışmalarda ailelerin çoğunlukla uygun dozda ateş düşürücü tedavi vermedikleri tesbit edilmiştir (1-4). Çocuklarda en yaygın olarak kullanılan ateş düşürücü, analjezik etkisinin de olması ve göreceli olarak güvenli olması nedeniyle asetaminofendir. İkinci sıklıkta kullanılan ateş düşürücü ise ibuprofendir.

Bu çalışmanın amacı, çocuk acile ateş yakınması nedeniyle başvuran hastalara aileleri tarafından evde verilen ateş düşürücülerin (parasetamol ve ibuprofen) uygun doz ve aralıkta kullanılıp kullanılmadığını araştırmak ve yanlış dozda ilaç kullanımını etkileyen etmenleri belirlemektir.

\section{Gereç ve Yöntem}

Çalışmaya Hacettepe Üniversitesi, İhsan Doğramacı Çocuk Hastanesi Çocuk Acil Birimi'ne 1 Ocak 2008-31 Mart 2008 tarihleri ve 08:00-16:00 saatleri arasında ateş yakınması ile başvuran ve bu nedenle hastaneye gelmeden önce en az bir doz parasetamol ve / veya ibuprofen almış olan 1 ay-16 yaş arasındaki çocuklar ileriye dönük olarak alındı. Tekrarlayan başvurular, verilen dozun ya da verilen ilacın adının ve yoğunluğunun tam olarak bilinmediği hastalar çalışma dışında bırakıldı. Çalışmanın yapılabilmesi için Hacettepe Üniversitesi Tıp Fakültesi Etik Kurul izni (HEK07/138-24) alındı.

Hastaların ailelerine sorulmak üzere 30 soruluk bir anket hazırlandı. Bu anket soruları arasında; yaş, cinsiyet, ağırlık, anne-baba yaşları ve eğitim düzeyleri gibi demografik bilgiler yanında; ateşin başlama zamanı, eşlik eden diğer bulgular, ateşli konvülziyon öyküsü, ateşi ölçme yöntemleri, verilen ateş düşürücünün adı, dozu ve sıklığı gibi ateşe ve kullanılan ilaca yönelik sorular yer alıyordu. Ayrıca ailelere çocukların acile getirilme nedenleri, ateş düşürücünün dozuna nasıl karar verildiği ve eğer ateş kontrol altına alınsaydı yine de acile gelip gelmeyecekleri soruldu. Verilen ateş düşürücünün dozunu tam olarak hesaplayabilmek için ilacın adı ve dozu öğrenildi. Asetaminofen için uygun doz aralığı $10-15 \mathrm{mg} / \mathrm{kg}$, verilme sıklığı 4 saat; ibuprofen için uygun doz aralı̆ı̆ 5-10 $\mathrm{mg} / \mathrm{kg}$, verilme sıklığı altı saat olarak belirlendi. Çalışmada ateş düşürücü ilacı uygun dozda alanlar ile uygun dozda almayan hastaların sonuçları karşılaştıııldı. Her iki ilacı ardışı olarak alan ve her ikisini de önerilen dozda alanlar, ilacı uygun dozda kullanan gruba alınırken; ilaçlardan birini doğru alamayanlar yalnış alan gruba dahil edildi. Ateş düşürücü dozunun doğru hesaplanabilmesi için hastaların tümünün kilosu hastanede yeniden tartıldı.

Anket formunu doldurarak çalışmaya katılan ailelere ateşe yaklaşım konusunda bilgilendirmenin yapıldığı bir broşür verildi.

Yanlış ateş düşürücü uygulanımını etkileyen etmenler student-t test ile belirlendi.

\section{Bulgular}

Çalışma süresi içinde, ateş nedeniyle çocuk acile başvuran, çalışmaya alınma ölçütlerini karşılayan ve anket formunu doldurmayı kabul eden 200 hastanın sonuçları değerlendirildi. Bu hastalar arasında parasetamol kullanan 131 hasta $(\% 65,5)$ ve ibuprofen kullanan 83 hasta $(\% 41,5)$ vardı. Bu hastaların 14'ünün (\%7) her iki ilacı ardışı olarak kullandığı görüldü. Hastaların demografik özellikleri Tablo 1'de verilmiştir.

\section{Tablo 1. Çalışmaya alınan hastaların demografik özellikleri}

\begin{tabular}{|l|c|}
\hline Yaş & $\begin{array}{c}4,5 \pm 3,2 \\
(1 \text { ay-13 y) }\end{array}$ \\
\hline Cinsiyet (kız) & $101(\% 50,5)$ \\
\hline Ağırlık (kg) & $18,6 \pm 9,5$ \\
& $(4-56)$ \\
\hline Anne yaşı & $31,6 \pm 5,6$ \\
& $(20-50)$ \\
\hline $\begin{array}{c}\text { Annenin eğitim durumu } \\
1-11 \text { yıl } \\
>11 \text { yıl }\end{array}$ & $145(\% 72,5)$ \\
\hline $\begin{array}{c}\text { Baba yaşı } \\
\text { Babanın eğitim durumu } \\
1-11 \text { yll } \\
>11 \text { yıl }\end{array}$ & $55(\% 27,5)$ \\
\hline $\begin{array}{l}\text { Anne dışında ateş düşürücüyü veren } \\
\text { ikinci kişi var mı? (Evet) }\end{array}$ & $35 \pm 5,9$ \\
\hline $\begin{array}{l}\text { Ateş düşürücü veren ikinci } \\
\text { kişinin eğitim durumu } \\
1-11 \text { yıl } \\
>11 \text { yıl }\end{array}$ & $126(\% 63)$ \\
\hline
\end{tabular}


Hastaların \%74'ünün (148 hasta) acile gelmeden önce ateşinin ölçüldüğü, \%24'ünün ise elle hissedilerek ateşi olduğuna karar verildiği, sadece dört hastanın gelmeden önce ateşinin hiç ölçülmediği öğrenildi. Hastaların 130'una (\%65) ateş düşürücü ile birlikte ateşi düşürmek için bazı geleneksel yöntemler de uygulanmıştı.

Çalışmaya dahil edilen 38 hastanın (\%19) düzenli gittikleri bir doktoru vardı. Acile gelmeden önce 56 hasta (\%28) başka bir doktora başvurmuştu. Bu hastalardan 38'ine $(\% 67,9)$ yakınmalarına yönelik olarak ilaç tedavisi önerilmiş, ancak hastaların \%13'ü önerilen ilaçları hiç kullanmaya başlamamıştı. Ateş hakkında sorulan önemli bazı sorulara verilen yanıtlar Tablo 2'de verilmiştir.

\section{Tablo 2. Ateş hakkında sorulan önemli sorulara verilen} yanitlar

\begin{tabular}{|c|c|}
\hline Ateș süresi (saat) & $\begin{array}{c}42,2 \pm 37,8 \\
(1-240)\end{array}$ \\
\hline Ölçülen en yüksek ateş ( $\left.{ }^{\circ} \mathrm{C}\right)$ & $\begin{array}{c}38,6 \pm 0,75 \\
(36-41,5)\end{array}$ \\
\hline Ailenin ateş olarak kabul ettiği değer $\left({ }^{\circ} \mathrm{C}\right)$ & $\begin{array}{c}37,7 \pm 0,8 \\
(35-40)\end{array}$ \\
\hline Ateşe eșlik eden diğer şikayetlerin varlığı & $156(\% 78)$ \\
\hline Ateşli konvülziyon öyküsü & $18(\% 9)$ \\
\hline $\begin{array}{l}\text { Hastaların çocuk acile getirilme nedenleri } \\
\text { Ateşin çok yüksek olması } \\
\text { Ateşin uzun sürmesi } \\
\text { Ateşli havaleden korkulması } \\
\text { Ateşin düşmemesi } \\
\text { Eşlik eden diğer şikayeti nedeniyle }\end{array}$ & $\begin{array}{c}73(\% 36,5) \\
26(\% 13) \\
30(\% 15) \\
20(\% 10) \\
61(\% 30,5)\end{array}$ \\
\hline $\begin{array}{l}\text { Kullanılan ateş düşürücünün } \\
\text { dozuna nasıl karar verdiniz? } \\
\text { Doktor önerisi ile } \\
\text { İlaç tanıtmalık bilgisi ile } \\
\text { Hemşire önerisi ile } \\
\text { Eczacı önerisi ile } \\
\text { Kendi bilgileri ile }\end{array}$ & $\begin{array}{c}120(\% 60) \\
53(\% 26,5) \\
4(\% 2) \\
9(\% 4,5) \\
14(\% 7)\end{array}$ \\
\hline $\begin{array}{l}\text { En sık eşlik eden şikayetler } \\
\text { Öksürük } \\
\text { Kusma } \\
\text { İshal }\end{array}$ & $\begin{array}{c}59(\% 29,5) \\
39(\% 19,5) \\
28(\% 14)\end{array}$ \\
\hline $\begin{array}{l}\text { Ateşi kontrol altına alsaydınız } \\
\text { acile gelir miydiniz? (Evet) }\end{array}$ & $116(\% 58)$ \\
\hline $\begin{array}{l}\text { Ateşin faydası var mı? } \\
\text { Evet } \\
\text { Hayır }\end{array}$ & $\begin{array}{c}37(\% 18,5) \\
163(\% 81,5)\end{array}$ \\
\hline $\begin{array}{l}\text { Ateşin zararı var mı? } \\
\text { Evet } \\
\text { Hayır }\end{array}$ & $\begin{array}{c}194(\% 97) \\
6(\% 3)\end{array}$ \\
\hline
\end{tabular}

Genel olarak hastaların \%54'ünün yanlış dozda ateş düşürücü kullandığı görüldü. Parasetamol verilen hastaların

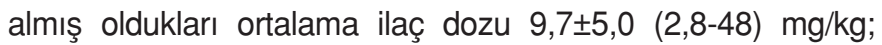
ibuprofen verilen hastaların almış oldukları ortalama ilaç dozu 7,0 $\pm 3,6(2,9-30,7) \mathrm{mg} / \mathrm{kg}$ idi. Hastalara verilen normal, düşük ya da yüksek dozda parasetamol ve ibuprofen dağılımı Şekil 1'de verilmiştir. Hastaların \%58,1'i düşük dozda, \%8,4'ü ise yüksek dozda parasetamol olmak üzere \%66,5'inin yanlış dozda parasetamol aldığı saptandı. İbuprofen alan hastaların ise \%27,7'si yetersiz dozda, \%9,6'sı yüksek dozda olmak üzere, \%37,3'üne yanlış dozda ibuprofen verildiği görüldü. Her iki ilacı da kullanan 14 hastanın \%50'si her iki ilacı da doğru almış, üçü her iki ilacı da yanlış almış, kalan dördü ise sadece parasetamol dozunu yanlış almıştı. Her iki ilacın alınması gereken sıklıkta verilip verilmediğine bakıldığında; hastaların \%40,5’i (60 hasta) ilacı önerilenden daha seyrek, \%33'ü (49 hasta) önerilenden daha sık ve \%26,4'ü (39 hasta) uygun sıklıkta almıştı (Bu soruyu yanıtlayan 148 hasta arasındaki oranlardır.).

Ateş düşürücü ilaçları yanlış ve doğru dozda kullanan hastalar Tablo 3'de özetlenen risk etmenleri açısından karşılaştırıldı. Sonuç olarak, çocuğun yaş ve kilosu arttıkça daha yüksek oranda yanlış dozda ateş düşürücü verildiği gözlendi $(p<0,01)$. Ebeveyn özellikleri değerlendirildiğinde ise; eğitim düzeyi ile uygun dozda ateş düşürücü verilmesi açısından istatistiksel olarak anlamlı ilişki bulunamadı ( $p>0,05)$. Buna karşılık genç ebeveynlerin daha yüksek oranda uygun dozda ateş düşürücü tedavi verdikleri görüldü $(p<0,01)$.

\section{Tartışma}

Bu çalışmada hastaların \%54'üne uygunsuz dozda (düşük ya da yüksek) ateş düşürücü tedavi verildiği, düşük dozda parasetamol $(\% 58,1)$ ve ibuprofen $(\% 27,7)$ alan hastaların çoğunluğu oluşturduğu görüldü. En sık ateş düşürücü olarak kullanılan parasetamol dozunun $(\% 66,5)$, ibuprofen dozuna göre $(\% 37,5)$ daha sık uygun olmayan dozlarda kullanıldığı saptandı. Çalışmamızda ateş düşürücü dozunun çoğunlukla doktorlardan öğrenildiği belirtilmesine rağmen; hastaların

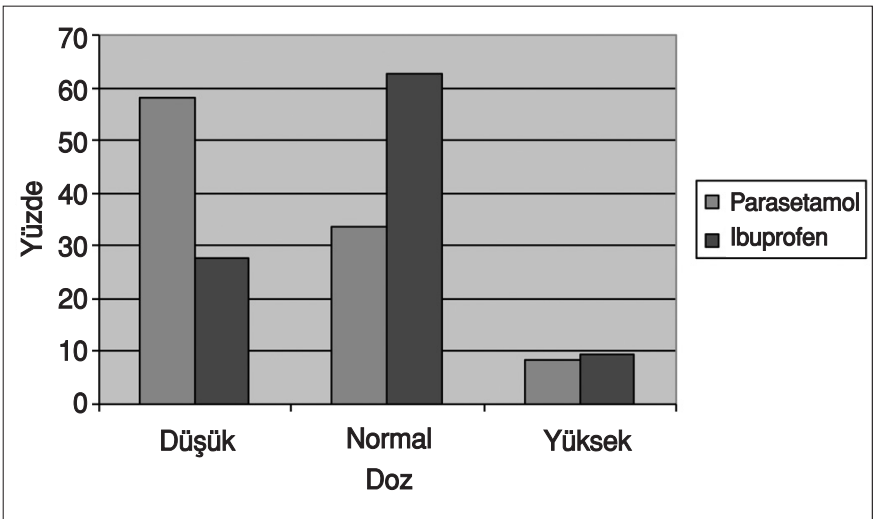

Şekil 1. Parasetamol ve ibuprofen verilen hastaların almış oldukları dozlara göre dağılımı 


\begin{tabular}{|c|c|c|c|}
\hline Risk etmenleri & $\begin{array}{l}\text { Uygun dozda } \\
\text { ateş düşürücü } \\
\text { alanlar }\end{array}$ & $\begin{array}{c}\text { Yanlış dozda } \\
\text { ateş düşürücü } \\
\text { alanlar }\end{array}$ & $p$ \\
\hline Yaş & $3,34 \pm 2,6$ & $5,57 \pm 3,3$ & $p<0,01$ \\
\hline Cinsiyet (kız) & $\% 42,6$ & $\% 57,4$ & $A D$ \\
\hline Ağırlık (kg) & $14,4 \pm 6,7$ & $22,2 \pm 10,1$ & $p<0,01$ \\
\hline Anne yaşı & $30,03 \pm 5,3$ & $32,7 \pm 5,6$ & $\mathrm{P}<0,01$ \\
\hline $\begin{array}{l}\text { Anne eğitim düzeyi } \\
\quad \begin{array}{l}111 \mathrm{yll} \\
>11 \mathrm{yll}\end{array}\end{array}$ & $\begin{array}{l}\% 46,2 \\
\% 47,3\end{array}$ & $\begin{array}{l}\% 53,8 \\
\% 52,7\end{array}$ & $\begin{array}{l}A D \\
A D\end{array}$ \\
\hline Baba yaşı & $33,4 \pm 5,8$ & $36,3 \pm 5,7$ & $\mathrm{P}<0.01$ \\
\hline $\begin{array}{l}\text { Baba eğitim düzeyi } \\
1-11 \mathrm{yll} \\
>11 \mathrm{yll}\end{array}$ & $\begin{array}{l}\% 42,1 \\
\% 52,7\end{array}$ & $\begin{array}{l}\% 57,9 \\
\% 47,3\end{array}$ & $\begin{array}{l}A D \\
A D\end{array}$ \\
\hline $\begin{array}{l}\text { Çocuğa primer bakan kişi } \\
\text { Anne } \\
\text { Diğer }\end{array}$ & $\begin{array}{l}\% 46,5 \\
\% 44,4\end{array}$ & $\begin{array}{l}\% 53,5 \\
\% 53,6\end{array}$ & $\begin{array}{l}A D \\
A D\end{array}$ \\
\hline $\begin{array}{l}\text { Bakıcı eğitim düzeyi } \\
1-11 \text { yıl } \\
>11 \text { yıl }\end{array}$ & $\begin{array}{c}\% 44,2 \\
\% 25\end{array}$ & $\begin{array}{c}\% 55,8 \\
\% 75\end{array}$ & $\begin{array}{l}A D \\
A D\end{array}$ \\
\hline $\begin{array}{l}\text { Başvuru öncesi } \\
\text { doktor viziti var }\end{array}$ & $\% 51,8$ & $\% 48,2$ & $A D$ \\
\hline Sürekli doktoru var & $\% 50$ & $\% 50$ & $A D$ \\
\hline $\begin{array}{l}\text { *Ateş olduğuna nasıl } \\
\text { karar verildi? } \\
\text { Ölçerek } \\
\text { Elle bakarak } \\
\text { Ölçmedim }\end{array}$ & $\begin{array}{c}\% 50 \\
\% 35,4 \\
\% 25\end{array}$ & $\begin{array}{l}\% 50 \\
\% 64,6 \\
\% 75\end{array}$ & $\begin{array}{l}A D \\
A D \\
A S\end{array}$ \\
\hline *Ateş süresi & $41,6 \pm 40,0$ & $42,7 \pm 36,0$ & $A D$ \\
\hline *En yüksek ateş & $38,6 \pm 0,85$ & $38,6 \pm 0,65$ & $A D$ \\
\hline $\begin{array}{l}\text { Ateş düşürücünün doz } \\
\text { bilgisinin kimden } \\
\text { öğrenildiği? } \\
\text { Doktor } \\
\text { Hemşire } \\
\text { Eczacı } \\
\text { Ilaç tanıtmallık } \\
\text { Kendisi }\end{array}$ & $\begin{array}{c}\% 45,3 \\
\% 45,8 \\
\% 75 \\
\% 33,3 \\
\% 50\end{array}$ & $\begin{array}{c}\% 54,7 \\
\% 54,2 \\
\% 25 \\
\% 66,7 \\
\% 50\end{array}$ & $\begin{array}{l}A D \\
A D \\
A D \\
A D \\
A D\end{array}$ \\
\hline
\end{tabular}

büyük çoğunluğuna verilen parasetamol ve/veya ibuprofen dozunun yetersiz olduğu ve doz aralığının da uygun sıkıkta olmadığı görüldü. Yanlış dozda ateş düşürücü verilme nedeninin, uygun ateş düşürücü doz bilgisinin artan yaş veya ağırlık ile güncellenmemesi olduğu düşünüldü.

Ateş düşürücülerin aileler tarafından doğru kullanılma sıklığını araşııran çalışmalarda, çalışmamıza benzer sonuçlar elde edilmiştir (3-8). Simon ve ark. (3) hastaların sadece \%40'ına uygun dozda ateş düşürücü verildiğini ve Linder ve ark.
(4) da ailelerin \%57'sinin uygunsuz dozda ateș düșürücü aldığını göstermiştir. Ateş düşürücülerin uygun dozlarda verilip verilmediğini araştıran bașka bir çalıșmada da çocuğa bakım veren kişilerin yarısının (\%51) verilmesi gereken ateş düşürücüyü yanlış dozda verdikleri, küçük çocuklarda (2 yaş altında) yanlış dozda ateş düșürücü verilme sıklığının daha fazla olduğu, çocukların ağırlıkları temel alınarak verilen ilaç dozlarının ise daha doğru olduğu saptanmıştı. Bu çalışmada da çalışmamızın sonuçlarına benzer şekilde, parasetamolün ibuprofene oranla daha sık düşük dozda verildiği saptanmıştır (Parasetamol \%47, ibuprofen \%12). Ayrıca hastaların yaşı temel alınarak verilen ilaç tanıtmalık bilgisi kullanıldığında dozun \%80'ininin, ağırlık temel alınarak verilen tanıtmalık bilgisi kullanıldığında dozun \%100'ünün doğru olduğu saptanmıştır. Küçük yaşlarda doz hatasının daha fazla oluşu ise, iki yaş altında ilaç tanıtmalık bilgisinin verilmemesi ile açıklanmıştır (5). Bilenko ve ark. (6) yaptığı çalışmada ise; daha düşük vücut ağırlığı olan ve rektal parasetamol alan çocukların önerilenden daha yüksek dozda ateş düşürücü aldığı saptanmıştır. Bu nedenle bu çalışmada da yaş değil, vücut ağırlığı temel alınarak doz hesaplaması yapılması ve ailelere eğitim verilirken ağırlığın dikkate alnması gerektiği önerilmiştir. Bu sonuçları destekleyecek şekilde, Mayıs 2011 tarihinde FDA (Food and Drug Administration) tarafından, Haziran ayında ise T.C. Sağlık Bakanlığı Illaç Eczacılık Genel Müdürlüğü tarafından kullanım kolaylığı sağlamak ve özellikle yüksek dozda parasetamol verilmesini önlemek amacıyla ilaç tanıtmalıklarda altı aydan itibaren doz bilgisinin olmasına karar verilmiştir.

Bizim çalışmamızda ise yaş büyüdükçe, ağırlık artıkça yalıış dozda ilaç verilme sıkığının arttığı görüldü. Çalışmamızda doktor önerisi ile doza karar verildiği söylense de, verilen dozların en son kullanılan dozda kullanıması ve yaş artıkça doz bilgisinin güncellenmemesi nedeniyle verilmesi gerekenden daha düşük dozlarda ateș düşürücü verildiği düşünüldü. Genç anne ve babaların ilacı daha doğru kullanmaya eğilimli olmasının nedeni, doz bilgisinin genç yaşlarda daha güncel olma ihtimalinin artması ile açıklandı. Ülkemizden yapılan bir çalışmada da ailelerin ateşle ilgili bilinç düzeyinin yeterli olmadığı, ateş düşürücü kullanımının eksik ve hatalı olduğu gösterilmiştir (9). Çalışmamızın sonuçları, daha önce yapılımış çalışmalarda da önerildiği gibi ailelerin ateş konusundaki bilgilerinin hastane ziyaretleri sırasında giderilmeye çalışılması gerektiğini desteklemektedir. Ancak bilgilendirmenin ne şekilde yapılması gerektiği konusunda da çalışmalar devam etmektedir. Doz bilgisinin doğruluk oranlarını arttırmayı amaçlayan bir çalışmada; ateş düşürücülerin kullanımı hakkında yazılı bir bilgilendirme yanında, grafik kullanılarak yapılan doz önerisinin doz hatalarını büyük oranda önleyebileceği, ancak tamamen engellemeyeceği gösterilmiştir (10-12).

Yirmi yıl kadar önce Schmitt (2), ailelerin ateşi olan çocuklarına çok sayıda yalnış uygulamaları ve düşünceleri olduğunu göstermiş ve bu gerçeğe çok uymayan düşünceleri "ateş korkusu" olarak adlandırmıştır. Ailelerin ateş korkusu nedenleri arasında; ateşin birtakım zararlı yan etkileri olduğuna inanmaları (\%94), ateşin çocuk için zararlı sonuçlar 
doğurabileceğine inanmaları (\%67), bir kısmının ateșin $38,9^{\circ} \mathrm{C}$ altında bile ciddi sonuçlar doğurabileceğine inanmaları gibi nedenler yer almaktadır $(2,13,14)$. Crocetti ve ark. (1) ates korkusunun günümüzde halen devam ettiğini göstermiştir. Çalışmalarında ailelerin \%91'inin ateşin zararlı etkileri olduğuna inandığı saptanmış; ateşli hastalık sırasında ailelerin çocuklarının ateşini sık kontrol ettikleri, ateş düşürücü vermek için sık uyandırdıkları, sık aralıklarla ateş düşürücü verdikleri, çoğunlukla normal vücut sıcaklığında bile ateş düşürücü tedavi kullandıkları saptanmıştı. Goldman ve ark. (7) yapmış olduğu bir başka çalışmada parasetamol verilen hastaların \%41'ine verilmesi gerekenden daha düşük dozlarda ateş düşürücü verildiği saptanmıştır. Bu çalışmada "eğer ateş kontrol altına alınabilseydi acile başvurmazdım" diyebilen hasta oranı \%54 olarak bulunmuştur. Bizim çalışmamızda ise hastaların \%58"inin ateşi kontrol altına alınsa bile acile başvuracağı saptandı. Bu sonuç, ateş korkusunun çalışmamıza katılan ailelerin önemli bir kısmında bulunduğunu gösterirken, ateşin yararlı olmadığı, zararlı olduğu yönündeki yanıtları ile bu bulgu desteklendi.

Sonuç olarak; ailelerin ateş düşürücü dozlarını sıklıkla yanlış kullandıkları ve neyse ki olması gerekenden daha düşük dozda kullanmaya eğilimli oldukları, verilmesi gerekenden daha sık ya da daha seyrek kullandıkları ve ateş korkusunun çalışma grubumuzda yaygın bir düşünce olduğu görülmüştür. Ailelerin ateş konusundaki bilgilerinin yeterli olmadığı ve hastane ziyaretleri sırasında ilacın dozu, sıklı̆̆ı, süresi ve ateş düşürücü içeren değişik formüller hakkında gereken bilgi eksikliklerinin giderilmeye çalışılması gerektiği düşünülmektedir. Ailelere eğitim verilirken ağırlığın dikkate alınması gerektiği vurgulanmalıdır. Ancak bilgilendirmenin ne şekilde yapılması gerektiği ve bu girişimlerin sonuçları hakkında daha fazla çalışmaya gereksinim vardır.

\section{Çıkar çatışması: Bildirilmemiştir.}

\section{Kaynaklar}

1. Crocetti M, Moghbeli N, Serwint J. Fever phobia revisited: Have parental misconceptions about fever changed in 20 years? Pediatrics 2001;107;1241-6.

2. Schmitt BD. Fever phobia: Misconceptions of parents about fevers. Am J Dis Child 1980;134:176-81.

3. Simon HK, Weinkle DA. Over-the-counter medications. Do parents give what they intend to give? Arch Pediatr Adolesc Med 1997;151;654-6.

4. Linder N, Sirota L, Snapir A, et al. Parental knowledge of the treatment of fever in children. Isr Med Assoc J 1999;1:158-60.

5. Li FS, Lacher B, Crain FE. Acetaminophen and ibuprofen dosing by parents. Pediatr Emerg Care 2000;16:394-7.

6. Bilenko N, Tessler H, Okbe R, Press J, Gorodischer R. Determinants of antiyretic misuse in children up to 5 years of age: Cross-Sectional study. Clin Ther 2006;26:783-93.

7. Goldman RD, Scolnik D. Underdosing of acetaminophen by parents and emergency department utilization. Pediatr Emerg Care 2004:20:89-93.

8. Alomar M, Alenazi F, Alruwaili N. Accuracy of acetaminophen dosing in children by caregivers in Saudi Arabia. Ann Saudi Med 2011;31:513-7.

9. Saz EU, Koturoğlu G, Duyu M, ve ark. Türk ailelerinin ateş yönetimi ile ilgili bilinç düzeyi ve korkuları. Çocuk Enfeksiyon Dergisi 2009;3:161-4.

10. Hixson R, Franke U, Mittal R, Hamilton M. Parental calculation of pediatric paracetamol dose: a randomized trial comparing the Parental Analgesia Slide with product information leaflets. Paediatr Anaesth 2010;20:612-9.

11. Hixson R, Gandhi M, Holton F. A randomised trial to evaluate prescribing accuracy when using the Paediatric Analgesia Wheel. Arch Dis Child 2009;94:268-72.

12. Yin HS, Mendelsohn AL, Fierman A, van Schaick L, Bazan IS, Dreyer BP. Use of a pictographic diagram to decrease parent dosing errors with infant acetaminophen: a health literacy perspective. Acad Pediatr 2011;11:50-7.

13. Betz MG, Grunfeld Af. 'Fever phobia' in the emergency department: a survey of children's caregivers. Eur J Emerg Med 2006;13:129-33.

14. Sullivan JE, Farrar HC, the Section on Clinical Pharmacology and Therapeutics; Committee on Drugs. Fever and antipyretic use in children. Pediatrics 2011;127:580-7. 